\title{
Nota de pesar: o falecimento do Prof. Dr. Carlos Eduardo Francischone.
}

Éber Coelho Paraguassu (1)

\section{EDITORIAL}

Lamento informar o falecimento, aos 71 anos, de Carlos Eduardo Francischone, um dos mais prestigiados profissionais da Odontologia brasileira e um dos pioneiros da Implantodontia no Brasil. Francischone faleceu na noite de quinta-feira (20/5) e fazia tratamento contra o câncer.

Marcado pela contribuição nas áreas de Dentística e Implantodontia, Francischone foi autor e colaborador de uma extensa produção acadêmica, incluindo livros, capítulos e artigos no campo de pesquisa. Como professor e palestrante, ministrou centenas de aulas tanto no Brasil como no exterior. Foi editor da revista Dental Press Implantology.

Na década de 1990, Carlos Eduardo Francischone desempenhou um importante papel na divulgação da Implantodontia osseointegrada no Brasil, ao lado do Prof. Dr. Laércio Vasconcelos, no acolhimento do Prof. Per-Ingvar Brånemark no Brasil.

"Ado", como era conhecido pelos amigos, era natural da cidade de Dois Córregos, no interior de São Paulo. No entanto, foi em Bauru que ele estabeleceu sua bem-sucedida carreira. A Faculdade de Odontologia de Bauru (FOB-USP) teve um importante papel em sua formação. Foi lá que ele fez sua graduação em Odontologia, em 1971, e iniciou uma próspera trajetória na docência. Foi lá também que obteve os títulos de mestre (1976), doutor (1978), livre-docente (1984) e professor titular (2000). Além de lecionar na instituição que o formou, Francischone também teve passagens importantes pela Universidade Sagrado Coração e na São Leopoldo Mandic. 
Instituição afiliada: 1- Specialized dentistry Group

Dados da publicação: Artigo recebido em 21 de Maio, revisado em 22 de Maio, aceito para

publicação em 25 de Maio e publicado em 30 de Maio.

DOI: https://doi.org/10.36557/2674-8169.2021v3n5p01-02

@ Éber Coelho Paraguassu dr.paraguassu@periodicosbrasil.com.br

This work is licensed under a Creative Commons Attribution 4.0 International

License. (c) (7) 